\title{
COMENTARIOS Y GLOSAS EN TORNO A Modernities de Peter TAyLoR
}

\author{
Guillermo A. Peimbert Frías
}

\begin{abstract}
En 1996 se publicó en español la primera edición del influyente texto Abrir las ciencias sociales, coordinado por Immanuel Wallerstein, en la editorial siglo XXI. Uno de los coautores es Peter Taylor, sociólogo y geógrafo, reconocido en el mundo académico aunque poco conocido en México. De él haremos algunos comentarios en estas notas: concretamente con relación a sus reflexiones sobre el tema de la modernidad que, consideramos, siguen siendo vigentes.
\end{abstract}

In 1996, the first edition of the influential text Open the Social Sciences, coordinated by Immanuel Wallerstein, was published in Spanish by Siglo XXI publishing house. One of the co-authors is Peter Taylor, sociologist and geographer well known in the academic world, though very little known in Mexico. It is about him that we will offer some commentaries in these notes: we will talk precisely about his reflections on the topic of modernity which we consider to continue to be relevant nowadays.

\section{La perspectiva geohistórica}

— 1 autor propone integrar, de manera muy pertinente, nuestra Urepresentación de la geografía mundial con la de la historia local, regional y global (procedimiento que él denomina método geohistórico). Esta perspectiva nos permite desnaturalizar los "mapas" con los que pensamos nuestro mundo. En primer lugar, para comprender la perspectiva geohistórica sobre la sociedad moderna, se

* Sociólogo y Doctor en Ciencias Políticas y Sociales. Académico del Centro Regional de Investigaciones Multidisciplinarias de la UNAM. 
requiere comenzar a pensar distinto: hay que trascender nuestra tradicional visión focalizada en los Estados individuales y alejar el zoom para no perder de vista el todo mundial.

Esta ambiciosa propuesta pretende integrar a las reflexiones de carácter político y económico (sobre el capitalismo y la formación de los Estados nación), una historia de larga duración que no pierde de vista los cambios (particulares y globales) en la vida cotidiana y en la subjetividad de los actores de cada época. Si bien no es válido generalizar a nivel global los cambios culturales, ignorando los contextos específicos de cada lugar y época, existen algunas características culturales hegemónicas a lo largo del planeta, que han venido convirtiéndose en verdaderos caballos de Troya de la modernidad. Acostumbrados como estamos a mirar la historia bajo enfoques más economicistas, resulta interesante, novedoso y muy esclarecedor que al hablar, por ejemplo, del proceso de urbanización, nos cuestionemos la historia de los artefactos tecnológicos más cercanos, como los baños al interior de las casas, la extensión de las cañerías por las ciudades, los usos particulares del espacio privado, del prestigio social que otorga su uso y las prácticas de vida cotidiana influenciadas por la circulación de formas simbólicas mediáticas, como el cine o la televisión.

\section{El ser modernos}

La significación positiva del término — que a partir del siglo XVI se fue cargando de optimismo-, hacia mediados del siglo XX comenzó su declive. Sin embargo todavía hoy millones de personas siguen considerando que denominarse o ser clasificados como modernos, los marca con un sello de prestigio. Con agudeza irónica, Taylor apunta al centro del problema cuestionando: ¿ha sido mejor la bomba nuclear que el arco y la flecha?

Ciertamente, para las ciencias sociales no se trata de condenar o defender la condición de ser moderno, sino comprender lo sucedido durante los periodos específicos en los cuales las ideas y las prácticas del "ser modernos" fueron creadas, desafiadas, cuestionadas y cam- 
biadas. La riqueza del trabajo de Taylor no sólo se encuentra en su alto nivel de generalidad y extensión histórica, que muchas veces se pierde de vista en las miradas más particulares, sino en la fundamentación empírica e histórica de sus afirmaciones.

Pero, ¿quiénes son los "modernos"? El llamado "desarrollo moderno" ha requerido la capacidad inventiva de individuos con actitudes y habilidades relevantes, producto de condiciones históricas específicas y no de una tendencia natural intrínseca a una supuesta "naturaleza humana".

Es importante tomar en cuenta que los "modernos" son hijos de ese sistema- mundo creado y desarrollado en lo que hoy llamamos Europa; los emigrantes europeos trataron de recrear posteriormente en otras latitudes, la imagen del viejo mundo. Esto se ve reflejado claramente en muchas constituciones que siguieron el modelo de una "madre patria".

\section{El malestar en la(s) modernidad(es)}

Las distintas acepciones del término modernidad apuntan a diferentes propósitos y provienen de distintos ámbitos: desde las perspectivas artísticas (del modernismo) que lo han conceptualizado como una "actitud mental", hasta aquellas miradas que parten de las ciencias sociales y que la definen (modernidad o modernización) como un proceso de cambio social y de desarrollo de los países "atrasados"; también encontramos teorías que prefieren conceptualizarla como un proceso de cambio cultural, social y económico de carácter inherente a la globalización.

Partiendo de esta multiplicidad de sentidos, Taylor propone utilizar el concepto como un paraguas que agrupe a todas estas experiencias. Sin embargo, el concepto mismo encierra una ambigüedad en su corazón, que tiene que ver con la poca credibilidad que ciertas teorías de la modernización tuvieron en el Tercer Mundo, lo cual se profundizó a partir de los años setenta del siglo XX. Cada vez más 
los teóricos reconocieron lo ambiguo del término para dar cuenta de los incesantes cambios sociales que venían dándose. ${ }^{1}$

Marshall Berman (1995) fue uno de los pioneros en pensar de otra manera la modernidad, reconociendo en su seno un perpetuo estado de malestar y desintegración, renovación y lucha, contradicción, ambigüedad y angustia.

Por otro lado, los trabajos de Boaventura de Souza Santos (p. ej. 2004) hicieron referencia a los dos pilares de la modernidad: la regulación y la emancipación. A la vez enfatizaron la paradoja vivencial del mundo moderno en el que hombres y mujeres experimentaron rápidos cambios que prometían grandes oportunidades, aunque éstas resultaran inalcanzables para la mayoría. A todo esto se añadía la conciencia de una posibilidad real de destrucción planetaria.

Desde el punto de vista de la vida cotidiana moderna que se iba legitimando y extendiendo por el mundo moderno, destacó el deseo de vivir confortablemente la propia vida a la vez que se experimentó una sensación cada vez más generalizada de inseguridad (la sociedad del riesgo de Beck, 2008).

Los regímenes modernos (fueran de izquierda o derecha) enarbolaron la racionalidad como bandera y pretendieron controlar el cambio a través de la burocracia planificadora. Las elites políticas de la Revolución Francesa y de la Francia napoleónica, juntamente con sus múltiples versiones fuera de Europa, experimentaron el proyecto administrativo de la modernidad. En la Unión Soviética, el mismo mecanismo de la planificación diseñó, al igual que en los Estados Unidos o Europa, crudos y deshumanizantes procesos de ingeniería social.

En este contexto de planificación generalizada orientada a controlar el cambio, la "planeación urbana" fue inventada en medio de la caótica situación de las ciudades del siglo XIX, a la vez que la "ciencia de la administración" planificaba la máxima eficiencia en los negocios, lo que significó para la mayoría de la gente, una exacerbación del malestar moderno. Podemos ver claramente, por

1 Como lo hicieron las teorías de la dependencia y las críticas desde la filosofía de la liberación (Marini, Dusell, etcétera). 
un lado, a la "gente moderna" y por el otro, a sus instituciones, aspirando a proyectos antitéticos de mundo. Estamos ante una batalla incesante entre los fabricantes del orden que pretenden controlar el incesante cambio y las aspiraciones individuales de libertad, confort y seguridad.

En medio de esta situación, la ciencia social norteamericana siguió defendiendo un falso optimismo. Y los teóricos soviéticos tampoco escaparon a esta quimera, compartiendo una imagen optimista del proyecto de la modernidad como sinónimo de industrialización. Las teorías sociales compartían un sistema simbólico de oposiciones que orientaba sus interpretaciones mediante la antinomia de lo industrial/moderno como opuesto a lo agrícola/tradicional: podríamos decir que se pensaba que sólo había una modernidad, y ésta era industrial. Fue hasta los años setenta del siglo XX cuando los teóricos de las sociedades post-industriales comenzaron a cuestionar la forma moderna de la condición industrial como única posibilidad. Así, roto este tabú, fue posible pensar en más de una modernidad.

\section{Hegemonías}

Los procesos de modernización son complejos y ocurrieron de manera diferencial y paralela. La "europeización” de los países del norte o centrales, fue distinta de la de las colonias o los países del sur. El siglo XX (era de la americanización del mundo bajo la hegemonía de los Estados Unidos de Norteamérica) es un claro ejemplo de cómo este proceso se produjo mediante una combinación de lo que Gramsci analizó con sus conceptos de hegemonía, coerción y consenso.

Al mismo tiempo que se dio la europeización de África, estaba dándose la americanización de Europa en la medida en que ésta se adaptaba a las prácticas económicas americanas ("la sociedad de la opulencia”). El poder americano que se vivió en el norte como hegemonía-consenso (en el sentido de liderazgo y dirección cultural) - a la vez que como "guerra fría" contra las potencias del "socialismo real" - , en el sur se vivió como una fuerza coercitiva y como un 
conjunto de guerras locales orientadas a la imposición del modelo llamado "liberalismo democrático" y a la defensa frente a la "amenaza comunista”. (Este proceso, llamado por los científicos sociales "modernización", también fue caracterizado por las descripciones populares como "cocacolización", "Mac Donalización” o la emergencia de la generación Levi’s y su extensión hegemónica por todo el globo occidental).

\section{De la hegemonía de clase a la hegemonía mundial}

¿Cómo explicar el alto nivel de consenso de las burguesías dominantes logrado en las llamadas sociedades "democrático-liberales" (en el largo plazo), en los países donde éstas devinieron hegemónicas, sin caer en simplificaciones maniqueístas?; ¿por qué las ideas de la clase dirigente se volvieron dominantes y orientaron las concepciones de la sociedad moderna? El concepto de modernidad puede pensarse junto con el de hegemonía (a pesar de provenir de diferentes tradiciones teóricas).

Taylor propone retomar la riqueza del concepto gramsciano de hegemonía, pero a una escala en la que los actores implicados no son las clases sociales, sino los Estados-nación. Así, al hablar de la hegemonía mundial de cada época, puede identificar diferentes Estados hegemónicos (como productores-orientadores de ciertas prácticas y representaciones más o menos aceptadas como legítimas en las llamadas "democracias liberales") que están implicados de manera crucial en el desarrollo del sistema mundo.

No hay que olvidar que el concepto gramsciano de hegemonía significa "liderazgo intelectual y moral" pero, en este caso, a escala del sistema-mundo. Los Estados hegemónicos son aquellos que son reconocidos por los otros como dignos de ser imitados. Un liderazgo no coercitivo se basa en la emulación social, y el estímulo crucial de este proceso es la representación de esa organización social como el futuro de todos los demás. De acuerdo con esta interpretación local de la hegemonía, el proceso de modernización no es algo 
que arrasa y destruye comunidades preexistentes, sino un proceso activo de construcción de algo nuevo que reemplaza lo anterior. En el caso holandés, el puerto de Ámsterdam, con cientos de grandes barcos en espera de descargar sus mercancías, fue la imagen de la modernidad a emular — para crear "nuevos Ámsterdam" como San Petersburgo (Berman, 1995)—; se trataba de reestructurar la configuración local de acuerdo al modelo deseable para el caso del mercantilismo comercial. Tanto Inglaterra como Francia emularon este modelo. En el caso británico, esta imagen fue la de Lancashire produciendo textiles para el mundo entero. Para emularlo, se requería de crear "nuevos Manchester" en otras tierras. A esta emulación se debe, según Taylor, la industrialización en el noreste de los Estados Unidos, y en Alemania, en la región del Rhin. En el caso de la hegemonía "americana", la imagen de los suburbia es tipificada por la ciudad de Los Ángeles, donde se origina el mito del consumo y de la oferta ilimitada de bienes y servicios accesibles a todos. En virtud del desarrollo de las tecnologías de información y comunicación, ya no era necesario visitar estas ciudades-suburbia presencialmente, ya que el cine o la televisión permitían visitarlas virtualmente y exponerlas como modelos que estimularon la emulación de la americanización consumista

\section{La periodización de las tres modernidades}

El uso del concepto gramsciano de hegemonía, ahora redimensionado a escala mundial, remite todavía a un liderazgo "moral e intelectual", pero ahora a nivel del sistema interestatal, lo que produce un impacto fundamental en la naturaleza socio-cultural del moderno sistema-mundo.

Siguiendo a Berman (1995), quien identifica tres fases principales de la modernidad, Taylor ubica la primera entre el siglo XVI al XVII, la segunda en el siglo XIX y la tercera en el siglo XX. Habla así de tres grandes ciclos hegemónicos mundiales a la vez que de tres consecutivos mundos modernos creados lentamente a través de los 
siglos: el ciclo ocurrido en los Países Bajos alrededor del siglo XVII, más específicamente en Holanda (que creó la modernidad mercantil), el de Gran Bretaña en los siglos XVIII-XIX (la modernidad industrial) y el de los Estados Unidos a partir de la segunda mitad del siglo XX (la modernidad consumista). Se trata de un proceso de larga duración ocurrido a lo largo de más de cuatrocientos años, que pasa de Ámsterdam a Londres y llega a Nueva York. El apogeo de las diversas hegemonías del ciclo se fue definiendo económicamente cuando el comercio, la producción y el capital financiero se sucedieron y apoyaron sistemáticamente, promoviendo cada uno de ellos, una supuesta "libertad": Holanda defendió la libertad de navegación, los británicos la libertad de comercio y los americanos la de libre empresa. Y en cada momento histórico, los intereses particulares de cada Estado fueron presentados y aceptados como universales.

Estos mundos modernos no emergieron de una "evolución natural" del sistema mundo, sino que aparecieron después de momentos bélicos determinantes que desembocaron en una nueva correlación de fuerzas: la Guerra de los Treinta Años (1618-1648), las guerras revolucionarias y napoleónicas (1792-1815) y la Primera y Segunda Guerras Mundiales (1914-1945); situaciones que generaron oportunidades inéditas para reestructurar un nuevo orden hegemónico.

La modernidad del liderazgo mercantil es holandesa, la del liderazgo industrial, británica y, finalmente, la del liderazgo consumista es norteamericana. Esto significa que los Estados hegemónicos lograron imponer los valores de sus elites dominantes en las relaciones sociales de cada época. Estos valores trascendieron las fronteras de sus Estados de origen y proveyeron estándares comunes para sus respectivas épocas: la era del mercantilismo, la era industrial y la era del consumismo. Estos son los tres "mundos modernos".

Desde el punto de vista cultural e ideológico estas fases pueden definirse como intentos intelectuales de: ordenar el conocimiento de las personas, dar cuenta del cambio social y — sobre todo- tratar de controlarlo. En este plano, el siglo XVII representa el mundo cartesiano que ha descubierto al hombre como su centro; el siglo XIX introduce la idea de cambio, interpretado como "progreso" 
humano; y el siglo XX recicla la idea de cambio presentándola como "desarrollo" dentro de la teoría de la modernización. Cada uno de estos paradigmas intenta aplicar el concepto de racionalidad en un contexto en el que cada vez más cobraba importancia la ciencia y la tecnología. Se trataba de racionalizar la novedad. Según Berman, esto puede ser interpretado como una reacción ideológico-cultural ante el incremento de las incertidumbres sociales.

Taylor sostiene que los fundamentos intelectuales de estas modernidades deben buscarse en la vida cotidiana de la gente ordinaria. Cada hegemonía está interconectada con una particular visión del mundo moderno. Estados y sociedades se convierten en promotores de la modernización, para tratar de controlar el cambio.

La modernidad mercantil fue emergiendo a partir de la cotidianidad del comercio y de los seguidores masivos que esta actividad generaba. Desde el siglo XVII una nueva racionalidad fue dominando al sistema mundo: la conducta calculada del comerciante fue el modelo arquetípico. El holandés, más que cualquiera, era considerado como alguien que fabricaba dinero "en forma respetable". La navegación fue el sitio de aplicación de la ciencia y de las nuevas instituciones del mercado (como la invención de la primera Bolsa de Valores en el mundo, allá por 1602 en Ámsterdam, principal centro financiero en aquella época a la vez que el más moderno centro de información). Es en esta segunda mitad del siglo XVII cuando aparece por primera vez la idea de la autoconciencia del mundo moderno, y cuando la Grecia y Roma clásicas son redefinidas como parte del panteón fundacional de esta identidad moderna (occidental).

A fines del siglo XVIII y principios del XIX la modernidad industrial alcanza una nueva e inédita escala de producción, gracias a nuevas fuentes de energía y la invención de máquinas y fábricas; en consecuencia, se alcanzaron nuevos niveles de acumulación de capital, principalmente en las zonas de producción. El gran comercio y la asignación de puertos cedieron su papel hegemónico a la acumulación masiva de población en centros urbanos industriales, que ahora figuraban como arquetipos de modernidad. La sociedad 
de masas alienadas (en el sentido de Marx) ${ }^{2}$ y de fábricas, se conjugó con el desarrollo de la ingeniería mecánica que jugó un papel importante en la orientación del cambio. El ethos victoriano fue favorable a la creación de una nueva confianza en el futuro basado en un progreso motivado por la tecnología (ciencia aplicada).

El siglo XX es el siglo de la expansión de la alienación en la gente común y corriente a una escala sin precedentes. Los Estados Unidos representan el mayor creador de consumistas distribuidos en los suburbia $^{3}$ de las ciudades y en centros comerciales ubicuos, convertidos en lugares focales de la modernidad. Esta modernidad se caracteriza por una estrecha relación entre producción y consumo masivos. Nuevas prácticas basadas en el scientific management y la organización científica del trabajo, crearon sus bases en el primer tercio del siglo $\mathrm{XX}$. Estas ciencias del management encontraron en las computadoras y las comunicaciones sus mejores instrumentos a fines del siglo XX. En tanto más se produce, el foco de la modernidad se va centrando en propiciar el consumo gracias al cual se podrá vender, y así, realizar el ciclo del capital. Y aquellos perdedores que no pueden realizar sus ansias de consumo (la mayoría), van perdiendo paulatinamente su optimismo.

Hablando en términos de larga duración, estas tres modernidades históricas han implicado dos cambios: un paso de lo mercantil a lo industrial y, más tarde, de lo industrial a la modernidad consumista. El primer gran cambio ocurrió entre la hegemonía holandesa y la británica (siglo XVIII). Lo que fue el gran optimismo social de la hegemonía holandesa dio paso a una obsesión nacionalista al declinar el siglo XVIII.

El gran cambio llamado Revolución Industrial (que no fue propiamente "político", ni se produjo a través de "guerras" tradicionales además de no haber dejado héroes), añadió al potencial mercantil previo la dimensión de una nueva producción (no esclavista) que

2 En los Manuscritos de 1844 y en el capítulo 1 de El Capital.

3 En los Estados Unidos los suburbia son extensas comunidades residenciales ubicadas en las afueras de la ciudad, constituidas principalmente por familias nucleares. Taylor presenta como ejemplo paradigmático los suburbia de la ciudad de Los Ángeles. 
revolucionó todas las relaciones sociales en el moderno sistemamundo.

En este proceso ocurrieron múltiples y diversos fenómenos: el tema de lo global fue delimitado por los Estados a la esfera de las políticas internacionales de cada país (asuntos externos); la expansión imperial dejó de privilegiar la conquista territorial mediante el control directo; se generaron comunicaciones globales (como los barcos a vapor, servicios postales y cables interoceánicos); las fuentes de energía fueron sustituyéndose por el petróleo — lo que generó la expansión de las máquinas de combustión interna (ferrocarriles, automóviles y más tarde aeroplanos)—; ; se dio una inédita expansión de los servicios eléctricos en hogares y fábricas; las fusiones corporativas dieron origen al capitalismo de oligarquías; se implementaron técnicas novedosas de dirección y gerencia orientadas a la producción en masa (a la vez que todo esto fue celebrado por los movimientos artísticos modernistas). Así, "América" devino en "la tierra del futuro" y la Gran Bretaña fue pasando a ser un lugar de nostalgia.

Cambios cruciales y silenciosos fueron produciéndose en la vida cotidiana después de 1880 en las ciudades americanas. La ética del antiguo mundo fue reemplazada por una nueva moralidad de "nuevos ideales de auto-realización e inmediata gratificación".

Taylor divide la historia de la hegemonía de la modernidad industrial norteamericana en dos grandes periodos: a) en 1920 Los Angeles mostró el camino hacia las nuevas estructuras urbanas - una metrópoli y sus suburbios - fundadas y basadas en el automóvil. b) Después de 1945, la instauración la sociedad de consumo y su aceptación por parte de las masas populares que fueron poco a poco, diciéndole "sí" a la hegemonía norteamericana ("yankees go bome... pero llévenme con ustedes").

4 Este proceso se puede ver en Briggs y Burke, 2002. 


\section{Las puertas de ingreso a la modernidad}

Es importante recordar que cuando hablamos de modernidad debemos evitar representarnos al mundo como un espacio singular y homogéneo. También hay que evitar la metáfora de que existen lugares que "reciben" la modernidad desde fuera. La geo-historia de las modernidades muestra que se deviene moderno a través de negociaciones por diversos caminos, en diferentes lugares y diferentes tiempos. $\mathrm{Y}$ es también importante recordar que las modernidades han sido marcadas tanto por la variedad local como por ciertas uniformidades que atraviesan lo particular.

Therborn (1995) ha identificado cuatro distintas "puertas de ingreso" a la modernidad: 1. La puerta europea de la reforma o revolución, 2. La de los "nuevos mundos" en América, 3. Aquella inducida por tratados externos y 4. La puerta abierta por las zonas colonizadas. Las relaciones de consenso (por imitación) básicamente han dominado las relaciones hegemónicas entre los países centrales así como las relaciones de coerción (por imposición) han sido dominantes más allá de los centros.

El Tratado de Westfalia de 1648, el de Viena en 1815 y los de Yalta y Postdam en 1945 pueden ser considerados como modelos de fin de guerra en los que no se obtuvo directamente un resultado de "beneficios territoriales" conquistados, como anteriormente ocurría. A estos estados de guerra se sucedieron, vía negociación, estados de paz (acompañados por supuesto de constantes y pequeñas guerras en otras partes del mundo). El resultado de estos tratados fue el reconocimiento de la hegemonía indiscutida de ciertos Estados, que serán emulados por los otros Estados centrales. Esto ocurre tanto en los procesos mencionados de mercantilización como en los de industrialización y americanización.

Como hemos dicho, la formación de países centrales sólo se explica si se observa la formación simultánea de los países y regiones periféricas. Más allá de los países centrales, la modernidad ha arribado mediante la coerción y se ha impuesto, ya sea mediante tratados, ya sea por la fuerza. En el primer caso, un grupo de elites políticas 
de los países periféricos acepta signar tratados impuestos desde el exterior, ante la amenaza de un estado de guerra, y consecuentemente presionan a sus pueblos para transitar por nuevos caminos. Hay casos de imposición de la industrialización desde arriba o, como ocurrió con las revoluciones de posguerra fría, casos en que la imposición de la modernidad consumista que se dieron a través de tratados externos (sobre todo después de los años ochenta del siglo $\mathrm{XX}$ ).

El uso de la fuerza para imponer la modernidad fue patente en el caso de las colonias desde el siglo XVII hasta el XIX y los dos ciclos del imperialismo. La imposición de la modernidad a través de la conquista creó pequeñas elites coloniales que sacaron ventajas con la reestructuración territorial que benefició al centro e introdujo a las periferias en la economía mundial, imponiendo las necesidades de los Estados dominantes a través de la explotación coercitiva del trabajo. La llamada era del Imperialismo globalizado (1870) creó periferias agrícolas productoras de materias primas al servicio de los países industrializados; todas las colonias cumplían una clara función y un rol en este sistema-mundial.

\section{El sistema de los Estados modernos}

A fines de la Guerra Fría, la práctica de las elecciones "democráticas" se generalizó representando una importante herramienta ideológica de los Estados Unidos en su conflicto contra la URSS. La democracia liberal puede considerarse como la forma política del Estado emanado de la hegemonía americana. Significa que los hombres y mujeres comunes podían tener una participación dentro de la hechura del gobierno.

Sin embargo, una de las maneras como las elites políticas se han protegido de la intrusión democrática real, ha sido la invención de una distinción norteamericana entre "alta" y "baja" política. La última compete a políticas económicas y sociales que tienen que ver con la vida ordinaria de la gente. La "alta" política que tiene que ver con la soberanía nacional y la seguridad ligada a ésta, y deriva histó- 
ricamente de las políticas de relaciones exteriores antes reservada al monarca y a sus asesores aristócratas. Esta distinción se sigue expresando - implícita o explícitamente- en las disciplinas de la ciencia política y en el estudio de las relaciones internacionales.

\section{La soberanía territorial: un nuevo absolutismo}

Poco a poco el concepto de soberanía nacional devino en un valor universal. En esta historia un evento es central: el Tratado de Westfalia (1648), donde por primera vez, los Estados se reconocen mutuamente como soberanos. Esta soberanía no se obtiene por auto declaración, sino por el reconocimiento externo, lo que implicará al mismo tiempo la voluntad reconocida de no intervención en los asuntos internos de cada Estado. Más tarde, en 1815, el Tratado de Viena representó un segundo momento importante y su resultado fue la hegemonía británica. Con la Organización de las Naciones Unidas se redefine en 1944 una nueva hegemonía mundial y serán los Estados Unidos los que ahora ocuparán este lugar.

En esta historia podemos ver la emergencia de un nuevo absolutismo, un nuevo political way of life en el que los espacios estatales son espacios absolutos; los políticos de cada Estado reconocen el derecho de los otros Estados a actuar libremente dentro de sus territorios, incluso aterrorizando a sus poblaciones, sin interferencias externas en sus políticas internas. Se trata de un verdadero absolutismo territorial instalado en el corazón de la política moderna. Y este fenómeno es absolutamente novedoso en la historia humana. El territorialismo fue así la solución a los conflictos religiosos antecedentes.

El concepto moderno de Estado se originó en el siglo XVI en Francia (nace la Razón de Estado). El Estado se instituye como fuente de poder orientada a la expansión de la acumulación de capital en toda la sociedad. Este proceso representó un cambio en la naturaleza de la territorialidad que no se conocía hasta ese momento 
Cuando más tarde la nueva racionalidad se focalizó en la soberanía nacional como base de los Estados, se descubrió al "pueblo" como fuente de legitimación. ${ }^{5}$ Esto también coincide con la emergencia de nuevas "comunidades imaginarias", esto es, de grandes colectivos que se que imaginaban como compartiendo un destino común (las naciones). La nación se concebía como un territorio compartido donde se debía defender la inviolabilidad e integridad de sus fronteras. El territorio nacional se volvía ahora el nuevo receptáculo cultural y, al asumir esta función, se volvía sagrado: representaba una fuente de identidad en la que no sólo se compartía un lenguaje, sino también un destino común.

Durante el siglo XX, el modelo de Estado-nación se vuelve ubicuo. Es el contenedor de las actividades políticas (de defensa), de las económicas (mercantilismo), de la identidad cultural (nacionalismo) y de una idea social (el Estado benefactor). Esta fusión de lo político, lo económico, lo nacional y lo social, convirtió al Estado en la institución más poderosa conocida hasta entonces. Pero pensar un Estado como entidad aislada y fuera del sistema de Estados, sería como imaginarse a un pez fuera del agua. Por eso la perspectiva geohistórica enfatiza la necesidad de enfocarse en la interestatalidad.

\section{La celebración de lo ordinario}

Enfocándonos en las similitudes de las sociedades civiles y los Estados, diremos que éstas no se deben analizar sólo desde el punto de vista económico: en este proceso también se han inventado nuevas representaciones socioculturales. Tanto Holanda, como Gran Bretaña y los Estados Unidos pueden ser considerados como pioneros en la invención de novedosas formas artísticas de celebrar lo ordinario, lo común y corriente; crearon innovadoras formas artísticas que develan similaridades entre las diferentes modernidades.

Las artes creativas fueron originalmente patrocinadas por el Estado o los mecenas. Esto fue cediendo el paso poco a poco a la

5 Ver Bolléme, 1990. 
mercantilización de los oficios, lo que significó, a nivel general, que los consumidores se fueran volviendo económicamente más poderosos que el Estado y los mecenas. El resultado novedoso e inusual fue que se dejaron de representar formas simbólicas ligadas a lo absoluto y excelso (Dios, Rey, cielo, tierra...) para dar paso a la representación de la gente común y corriente. Este proceso de tres ciclos hegemónicos transcurre a lo largo de cuatro siglos.

Cada sociedad civil hegemónica fue excepcionalmente innovadora en la creación de artes y nuevos tipos de mercado. Los holandeses lo reflejaron en la pintura, los ingleses en las novelas y los americanos en el cine y la televisión. A pesar de las enormes diferencias en los medios, se fue representando cada vez más la vida cotidiana de la gente común y corriente. Esta celebración de lo ordinario es algo poco común desde el punto de vista histórico.

\section{La pintura, la novela, el cine y la televisión}

La cultura del absolutismo fue el barroco, que glorificó a los reyes y a la Iglesia. Originada en la Iglesia, esta cultura intentó reproducir simbólicamente el cielo en la tierra. Se sabía del poder de inculcación y de seducción de las imágenes y de los artefactos culturales que impresionaban a los súbditos y a los rivales. El Palacio de Versalles de Luis XIV (el Rey Sol), la "música culta” (clásica), las esculturas heroicas y las pinturas gloriosas, dejaban ver a Dios en la tierra y su divina voluntad hecha realidad.

Pero Holanda inventó una "pequeña tradición”. En sus pinturas se puede ver el desarrollo de un nuevo estilo que contrasta con el barroco, y que ahora incluía retratos con escenas mundanas: la realidad cotidiana de la gente ordinaria, sus hogares, el mundo cívico y rural, la vida de los soldados, los médicos, los barcos, etcétera. En suma, un realismo que ya no refleja a Dios sino a los hombres de carne y hueso, como un espejo de la cotidianidad y del medio ambiente (paisajes). Además, la pintura holandesa es la primera que se mercantiliza volviéndose un negocio para clases medias. En 1650 se estiman entre dos y medio millones de pinturas vendidas. Las 
nuevas mercancías se destinan a la nueva burguesía sin realeza ni religión, sin filosofía y en búsqueda de confort y lujuria. En las pinturas aparece gente trabajando, en la trivialidad del confort burgués o en las labores cotidianas.

En el siglo XVIII y XIX emergió un mercado cultural completamente diferente al anterior, ahora en la Gran Bretaña. Se trataba ya de una nación de lectores y autores. En Londres, el número de impresores se incrementó de 70 en 1724 a 372 en 1802; éstos imprimían periódicos, revistas, panfletos y libros. Fue posible también gracias al incremento de los hogares de clase media con una nueva configuración (la familia burguesa), donde las mujeres cumplían funciones específicas en la administración del hogar y se hacía un uso nuevo del tiempo libre. En este contexto la novela jugó un papel análogo al de la pintura holandesa en la celebración de lo ordinario: sus argumentos originales tomaron un giro individualista con mitologías de la abstinencia en las que la experiencia individual era siempre única. Se trataba de actores particulares en contextos particulares. Así, la literatura se convirtió en el vehículo subjetivo del mundo cambiante en la era de la novela victoriana (1840-1888), donde se reflejaban las preocupaciones por el mundo de la vida popular, pero a la vez, donde se diferenciaban claramente la clase media de la aristocracia y de las clases trabajadoras sometidas a la disciplina laboral.

Ya para el siglo XX, este mundo ordinario se puede ver reflejado en el cine. En 1925, millones de personas en Europa reconocían fácilmente las caras y los nombres de las estrellas cinematográficas, a la vez que desconocían los del primer ministro de su país. Ya para los años treinta, Hollywood proporcionaba un escape simbólico a la pobreza mediante los resplandores estelares de sus filmes espectaculares. Tal fue la conciencia de la importancia que esto representaba, que las legislaciones comenzaron a controlar los estudios de filmación, y los conocidos despidos de presuntos comunistas no se dejaron esperar en su afán de eliminar el radicalismo artístico. Las audiencias norteamericanas llegaron a la cima en 1946 y la explotación de este mercado seguía a la alta. Poco después, la televisión comenzaría su ascenso hasta llegar a desplazar poco a poco al cine. 
Un nuevo estilo de vida se instaló rápidamente en la posguerra. Ya para los años 50, la televisión competía fuertemente con sus producciones de 50 minutos: filmes domésticos, comedias y dramas ligeros fueron adquiriendo cada vez más importancia. En ellos se reflejaba la vida americana como segura, acogedora y doméstica. De este modo el "sueño americano" fue extendiéndose gracias al celuloide.

También por los años 50 se descubrió un nuevo mercado que generó un gran negocio: los filmes de adolescentes (los teenagers), en los que se mostraba una importante innovación cultural: el amor, la rebelión, los conflictos, las escuelas, la sexualidad, el humor... Era la juventud "común y corriente", producto de la afluente sociedad americana. Este nuevo mercado generó nuevos consumidores, asociados al uso del tiempo libre, al placer y al consumo de ostentación. El rock and roll, las historias de amor, las diversiones en la playa, etcétera, recogían las preocupaciones adolescentes que ahora eran comercializadas. El sistema Hollywood produjo semidioses, las máquinas de promoción publicitaria generaron estrellas que representaban a "personas ordinarias" pero, a la vez, formaban ídolos en los que se proyectaban simbólicamente toda clase de deseos: Gregory Peck, Doris Day, Rock Huston, etc.

\section{El hogar moderno y los suburbia: sintiéndose confortable}

Bajo la ideología de que el "progreso material", definido en términos consumistas, era algo inevitable, la invención del "dinero de plástico" permitió aumentar las expectativas consumistas. La promesa del confort para todos, las comodidades "modernas", la feliz convivencia, la eficiencia, el derecho a la recreación, la facilidad en el uso de las cosas, el placer como meta, el disfrute de la intimidad y la privacía, eran algo cada vez más deseable. En contraste con las 
anteriores civilizaciones, el confort moderno estaba aparentemente al alcance de cualquiera, de hombres y mujeres ordinarios, de los descendientes de los antiguos esclavos y siervos.

La estructura arquitectónica del confortable hogar moderno comenzaba con un ball (la entrada, el vestíbulo): un cuarto pequeño que servía de entrada, con escaleras, cortinas y ventanas. ${ }^{6}$ En el hogar moderno el hall es una zona fronteriza de transición entre un exterior público y el interior privado. Es la frontera moderna entre los visitantes que tienen derecho a pasar (amigos) y los de afuera (que no pasarán). El hallno es un lugar confortable sino de paso en el que no se espera una larga estancia. El invitado podrá pasar a la sala, si se le invita y se queda, compartiendo el confort, o se despedirá ahí mismo. Más tarde, el primer piso separaba el espacio público del privado. Las paredes de la acogedora casa se adornaban con pinturas.

El sentido moderno del confort se inventó en el siglo XVIII en Holanda cuando la nueva economía estimuló nuevas conductas culturales. Los comerciantes holandeses orientaron a las familias a vivir en hogares pequeños, con pocos sirvientes: cuidadoras y maestros particulares de niños (que así fueron integrados mercantilmente a la vida familiar). De este modo los holandeses inventaron, en este nuevo contexto, lo que hoy conocemos como "infancia".

En el siglo XVIII el confort en el interior del hogar avanzó en dos sentidos: en la Francia aristocrática el gusto "exquisito" se manifestó en los palacios; en la Inglaterra burguesa, la corte de Hanover y el estilo gregoriano influenciaron los gustos. Las sillas "chipandale" (confortables y fáciles de usar) se mezclaron con las nuevas prácticas culturales como el juego de cartas, las comidas de cumpleaños, el billar, las danzas y la lectura de novelas.

Pero el mayor cambio en el confort ocurrió en Inglaterra a lo largo del siglo XIX con la invención de la plomería y las tuberías en el hogar; con el uso de la luz eléctrica, la calefacción y los muebles confortables.

6 A diferencia del hogar medieval en el que el vestíbulo tenía un uso por definición público - con jardines- donde se trataban negocios, se cocinaba y comía, y donde se programaban espectáculos de entretenimiento nocturno. 
Posteriormente, el confort en el hogar, que antes dependía de los sirvientes, comenzó a depender de un pequeño invento: el motor eléctrico (en lavadoras, licuadoras, etcétera). La electricidad en el hogar comenzó a utilizarse simultáneamente en Inglaterra y Estados Unidos en 1877. La gran diferencia se produjo en Nueva York, cuando Edison cableó 200 casas que usaron 5000 bombillos. Al poco tiempo se tendieron masivamente cables eléctricos, lo que motivó el consumo de aparatos domésticos: planchas, aspiradoras, lavadoras, máquinas de coser, ventiladores, tostadores, hornos, etcétera. Ya para mediados de 1920 el 60\% de los hogares norteamericanos tenía electricidad y consumía más de la mitad del mercado mundial. Esto redujo el precio de la electricidad y permitió el desarrollo de la sociedad de consumo.

Los norteamericanos diseñaron el cuarto de baño como un espacio para el aseo personal y el uso de la moderna taza de baño. Su generalización ilustra cómo la modernidad se volvió parte de la vida de millones de personas en el siglo XX. Estos baños requerían, a su vez, una nueva macro infraestructura de redes eléctricas e hidráulicas, drenajes y abastecimientos de agua potable. Por último, los norteamericanos concibieron algo muy distinto a lo que hasta entonces se conocía: los suburbia. Se trata de espacios convenientemente integrados a la vida urbana. Los suburbia son un nuevo y distintivo fenómeno geográfico que funciona como espacios de concentración del confort.

Si las aportaciones holandesas e inglesas se hicieron a nivel del hogar, las americanas se hicieron a nivel de los suburbia. En consecuencia, los hogares se integraron homogéneamente en un nuevo medio ambiente con obligatoriedad del confort.

\section{Los suburbia como el terreno del consumidor doméstico}

Estrictamente hablando, desde el punto de vista geográfico los suburbia son tan antiguos como el crecimiento urbano. Son el lugar donde cada familia trata de mantenerse fuera de la influencia de la 
corrupción urbana y se reubica en las zonas rurales contiguas a la ciudad. En los suburbia norteamericanos de la modernidad consumista se pueden observar los hogares integrados por familias nucleares, cada una de las cuales tiene su jardín privado, al que se llega por una calle moderna (pavimentada, asfaltada...)

Para los británicos, los suburbios se concebían como un espacio excluyente. La aportación americana popularizó la idea de los suburbia como una meta para cualquier familia: "un espacio para todos". Y no es que los americanos hayan eliminado la idea de exclusión, sino que la pensaban en gradaciones: todo de acuerdo a los diferentes presupuestos. Todo esto ocurre a partir de la década de los años cincuenta, que es cuando se produce el mayor nivel de crecimiento demográfico en la historia de los Estados Unidos, a tal grado que para 1960 había ya 19 millones de personas más viviendo en los suburbia, comparado con el año 1950.

A gran escala, la suburbanización se produjo a fines del siglo XIX tanto en los Estados Unidos como en Gran Bretaña como resultado de las innovaciones en los transportes urbanos, el ferrocarril, el trazado de calles en patrones lineales y la facilidad de movilidad. Más tarde esto se generalizó a una escala todavía mayor con la aparición del automóvil.

La ciudad de Los Angeles, con el más alto índice de autos per cápita: era la ciudad del automóvil. Aquí la clase media consumista en busca de confort se universalizó. Esta tierra del consumista moderno representó la culminación de cuatro siglos de modernizaciones. Fue el monumento del mundo moderno americano.

Por último no hay que olvidar que todo este proceso ha tenido sus críticos, para los cuales la ciudad norteamericana con sus grandes suburbia representa la muerte del urbanismo civilizado a la vez que la democratización del confort, uno de los orígenes del despilfarro contaminante que más efectos perversos ha generado.

Finalmente, ya desde el siglo XX se pueden observar signos claros de la tendencia a la baja de esta hegemonía norteamericana que no logró cumplir sus expectativas como para seguir siendo la ideología hegemónica. 


\section{Bibliografía}

Beck, Ulrich, 2008, La sociedad del riesgo mundial: en busca de la seguridad perdida. Ediciones Paidós Ibéric

Berman, Marshall, 1995, Todo lo sólido se desvanece en el aire. La experiencia de la modernidad. México. Siglo XXI.

Bolléme, Genèvieve, 1990, El pueblo por escrito: significados culturales de lo "popular". México, CONACULTA

Briggs Asa y Meter Burke, 2002, De Gutemberg a Internet: una historia social de los medios de comunicación. Madrid, Taurus.

Dussel, Enrique, 2007, "La filosofía de la liberación ante el debate de la posmodenidad y los estudios latinoamericanos". En: Jáuregui y Moraña. Colonialidady crítica en América Latina. México. Universidad de las Américas.

Marini, Ruy Mauro, 1991, Dialéctica de la dependencia. México. Era.

Marx, Karl, 1980, "Manuscritos económico-filosóficos de 1844". En: Marx y Engels. La sagrada familia. España, Grijalbo.

— 2001, "El fetichismo de la mercancía." El capital, Tomo 1, vol. 1. México, Siglo XXI.

Sousa Santos, Boaventura de, 2004, Democratizar la democracia. Los caminos de la democracia participativa. México, FCE.

Taylor, Peter J., 1999, Modernities. A Geohistorical Interpretation. University of Minnesota Press.

Therborn, Goran, 1995, European Modernity and Beyond. The Trajectory of European Societies 1945-2000. Sage.

Wallerstein. Immanuel, 1999, El moderno sistema mundial. La agricultura capitalista y los orígenes de la economía-mundo europea en el siglo XVI. Madrid: Siglo XXI Editores, 1979. Tres tomos. 